Title Page

Adverse Effects of Antidepressants Reported by a Large International

Cohort: Emotional Blunting, Suicidality, and Withdrawal Effects.

John Read ${ }^{\text {a }}$ (corresponding author) James Williams ${ }^{\text {b }}$

a School of Psychology

University of East London

Stratford, London E15 4LZ, UK

john@uel.ac.uk

$+44(0) 7944853783$

b Department of Psychological Sciences

Swinburne University of Technology

Melbourne, Australia 


\title{
Adverse Effects of Antidepressants Reported by a Large International Cohort: Emotional Blunting, Suicidality, and Withdrawal Effects.
}

\author{
Abstract: \\ Background: Studies of the adverse effects of antidepressants tend to focus on biological \\ symptoms. The prevalence of suicidality and withdrawal effects are currently a source of \\ controversy.
}

Objective: To directly ascertain the experiences of an international sample of antidepressant users.

Method: An online survey asked adult antidepressant users whether they had experienced 20 adverse effects 'as a result of taking the antidepressant', and if so, to what degree of severity. 1,431 people from 38 countries responded.

Results: $61 \%$ of the respondents reported at least ten of the 20 effects, most commonly: 'Feeling emotionally numb' (reported by 71\%), 'Feeling foggy or detached' (70\%); 'Feeling not like myself' (66\%), 'Sexual difficulties' (66\%), 'Drowsiness' (63\%), and 'Reduction in positive feelings' (60\%). 'Suicidality' as a result of the drugs was reported by $50 \%$.

Withdrawal effects were reported by $59 \%$, and 'Addiction' by $40 \%$. Rates of adverse effects were higher for those prescribed multiple antidepressants and those who also took antipsychotics. Younger age and longer use of ADs were positively related to total adverse effects. One third did not recall being told about any side effects by the prescriber. Less than $5 \%$ were told about suicidality, emotional numbing, withdrawal effects or addiction.

Conclusions: Asking people directly reveals far higher rates of adverse responses to antidepressants than previously understood, especially in the emotional, psychological and interpersonal domains. Given recent findings that antidepressants are only marginally more effective than placebo, the findings of the current study imply a cost-benefit analysis that cannot justify the extremely high prescription rates for these drugs. 
Keywords: Adverse effects, antidepressants, depression, emotional numbing, side effects, suicidality, withdrawal effects. 


\section{INTRODUCTION}

Prescription rates for antidepressants (ADs) are high and increasing [1]. One in eight adults in the USA were prescribed ADs by 2012 [2]. In 2016, England had 64.7 million prescriptions for a population of 55.3 million. This was double the prescriptions in 2006 and means that about one in seven women and one in 13 men are currently receiving antidepressants in England [3]. These extraordinary prescription rates are difficult to understand in terms of evidence-based cost-benefit analyses. Less than half of trials find ADs superior to placebo [4], with properly blinded studies particularly unlikely to find any difference to placebo $[5,6]$. An early meta-analysis found that 'the overall effect of newgeneration antidepressant medications is below recommended criteria for clinical significance' [7]. A recent meta-analysis [8] reached much more favorable conclusions but the median duration of treatment in the included studies was just eight weeks and studies were excluded if $20 \%$ or more of the participants were 'treatment- resistant' (i.e. it was known that the drugs did not work for them) were excluded. Furthermore the meta-analysis paid no attention to adverse effects. Another recent, more rigorous, meta-analysis [9], of 131 placebo-controlled trials, which did include adverse effects, again found that the overall effect size does not reach the threshold for 'clinical significance' and also found that ADs produce significantly more 'serious' and non-serious' adverse effects than placebos. It was concluded that 'The potential small beneficial effects seem to be outweighed harmful effects of SSRIs versus placebo for major depressive disorder seem to outweighed by harmful effects' [9]. Of particular relevance to the current study was the finding that 'There was almost no data on suicidal behavior, quality of life and long-term effects'.

Studies, and checklists, of these harmful effects have indeed focussed on biological or medical effects. Of the 84 adverse events reported by the 2017 meta-analysis to have been studied at least once, almost all were biological/medical reactions. The eight effects most 
often assessed in the 131 drug trials were: nausea, headache, dry mouth, insomnia, somnolence, diarrhea, dizziness and constipation effects' [9]. Both the 'Antidepressant SideEffect Checklist' [10] and the 'Patient-Rated Inventory of Side Effects (PRISE)' [11] focus almost exclusively on these bio-medical phenomena and fail to address the psychological or interpersonal domains (although some, such as sexual impairment, can be seen as both biological and interpersonal).

A 2013 review [12] of the few, relatively small scale, studies of the actual experiences of AD users [e.g. 13-17] identified multiple adverse effects relating to quality of life, in the psychological, emotional and interpersonal domains. These included emotional detachment, a belief that ADs prevent natural sadness, harmful effects on relationships, caring less about self and others, fear of addiction, and suicidality. For example of 468 descriptions of adverse effects by $\mathrm{AD}$ users on a website the most frequent were sedation, impaired cognition, reduced libido, emotional blunting, activation (arousal, insomnia, agitation) and emotional instability [14].

The largest survey of AD users to date [18] identified surprisingly high rates of adverse effects among 1,829 New Zealanders, especially in the personal and interpersonal domains. These included: Sexual difficulties (62\%), Feeling emotionally numb $(60 \%)$, Feeling not like oneself (52\%), Agitation (47\%), Reduction in positive feelings (42\%), Suicidality (39\%), and Caring less about others (39\%). It also identified high rates of Withdrawal effects (55\%) and Addiction (27\%).

The New Zealand survey reflects the growing interest in the views of 'experts-byexperience' in general and of Patient-Reported Outcome Measures (PROMs) in particular. These tools are increasingly recognized as an essential component of the governance of healthcare systems and the assessment of drugs, with a particular focus on understanding whether health care [19] and mental health care [20] are beneficial and safe. The current 
study aimed, therefore, to expand our knowledge of the first-hand experience of people who take ADs by replicating the New Zealand study with a similarly large, but international, sample.

\section{METHODS}

\subsection{Instrument}

'The Experiences of Anti-depressant and Anti-psychotic Medication Survey' was developed for this study (https://swinuw.aul.qualtrics.com/jfe/form/SV_0jPOxpXhPLNZjmZ). It was in English, with no translations made available. The anti-depressant sections of the questionnaire were based on the New Zealand 'Views on Antidepressants' questionnaire [18, 21-23]. The questionnaire generated quantitative (yes/no and multiple-choice questions) and qualitative data (open-ended questions), about: the prescribing experience, the positive and negative effects of medications, causal beliefs about psychosis/depression, alternative treatments, experiences of withdrawing from the medications, and demographics,

The current paper reports the adverse outcomes of the AD section. Adverse effects were assessed with the question 'Please rate the following side effects you may have experienced as a result of taking the anti-depressant', followed by a list of 20 effects and the options to respond to each with 'Not at all', 'Mild', 'Moderate' or 'Severe' (see Table 2). Three of the 20 side effects in the original 'Views on Antidepressants' questionnaire were not included; two because they were the least frequently endorsed ('Diarrhoea' - 20\% and 'Weight loss' $15 \%$ ), and one, 'Failure to reach orgasm', because it was covered by 'Sexual difficulties'. These three were replaced with three new items that had been spontaneously reported by numerous participants: 'Insomnia', 'Feeling foggy or detached', and 'Distorted dreams' [18]. Participants were also invited to report 'Other' side effects. They were further asked (in a 
Section titled 'When you were first prescribed anti-depressant') 'Did the doctor inform you of any possible side effects?' (Yes/No) and 'If Yes, what side effects were mentioned?'

\subsection{Participants}

Of the 2,346 people who responded 668 were recruited via an Australian online research company, and 1,678 people via advertisements on social media and snowball sampling. Of the 2,133 who had taken ADs, 42 were deleted because they ticked 'no' when asked to confirm that they met the following criteria: 'I have been taking or have previously taken antidepressant medication continuously for at least one month for any reason'; 'I am aged 18 or older'; and 'I am not currently compulsorily detained in a psychiatric hospital'.

Among the remaining 2,091 responses, the 44 that responded to 'What is the name of your current or most recent anti-depressant medication?' with a drug that is not an anti-depressant were deleted (most commonly valium - 16, xanax - 7 and lithium - 5). There were 39 responses emanating from the same Internet Protocol (IP) address as another response, indicating use of the same computer. Of these 39,33 were deemed a repeat response by the same person (based on identical demographics or very similar responses) and were deleted. Of the remaining 2,014, 497 completed the demographics section but very few or no questions in the $\mathrm{AD}$ section, leaving 1,517. The questions about adverse effects were not answered by 86 people. This left 1,431 for the analyses for this paper (see Figure 1). 
Figure 1. Flowchart of participants.

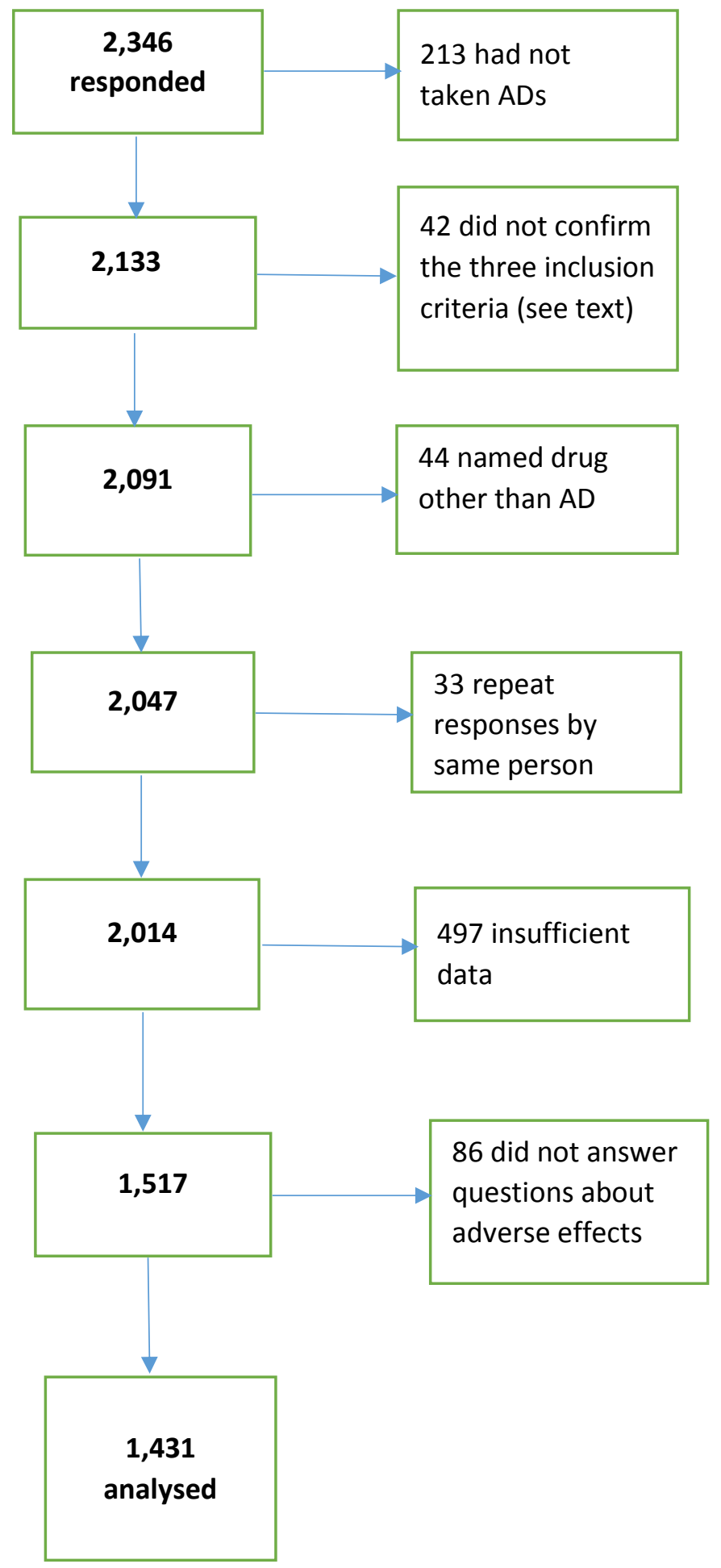




\subsection{Data Analysis}

A Total Adverse Effects (TAE) score was calculated by combining the scores $(0-3)$ for the 20 side effects, producing a potential range of 0 to 60 . (There were 57 responses with between one and four empty boxes in the adverse effects section and these were scored as '0'- 'not at all'). The TAE thereby incorporates both the frequency of different adverse effects and their severity. Spearman Rank Order Correlation Coefficients (rho) were used to test for relationships between dimensional variables, e.g. age and likert scale measures of adverse effects. Independent sample, two-tailed t-tests were used to explore differences between mean scores in relation to gender, duration of treatment ( $\leq 3$ years vs $>3$ years) and types of drug. The level of significance was set at the $p<.01$ level because of the high number of tests and the consequent risk of false positives.

\section{RESULTS}

\subsection{Sample Characteristics}

Of the 1,517 participants, 1,018 (67.1\%) had taken only ADs, and $499(32.9 \%)$ had also taken APs. When completing the survey 813 (53.6\%) were still taking ADs. Of the 1,497 who reported how long they had taken APs, $6.2 \%$ responded less than three months, $14.7 \%$ said 3 to 12 months, $16.5 \%$ one to three years, and $62.5 \%$ more than three years. The initial prescriber was a GP in $61.7 \%$ of cases and a psychiatrist in the other $38.3 \%$.

The majority of respondents (70.5\%) were women. Respondents' ages ranged from 18 to 78 and averaged 45.1 (s.d. 13.5), with no gender difference. Half (50.7\%) were employed; $14.8 \%$ were unemployed; $7.3 \%$ were students; and $27.2 \%$ ticked 'other'. The most common responses to the open question 'What ethnicity or cultural group do you most identify with?' were: 'White' or 'Caucasian' (47.9\%), 'Australian' (21.8\%), 'British'/'English'/'Anglo' (12.3\%), 'European' (8.0\%), 'New Zealander' (3.0\%) and 'Asian' (1.5\%). 
IP addresses showed that the 1,517 respondents lived in 38 countries, most commonly Australia (667; 44.0\%) (from where the survey was conducted), the UK $(277 ; 18.3 \%)$, and the USA (247: 16.3\%). The nine other countries with more than 10 respondents were: New Zealand (61), Germany (48), Denmark (31), Canada (30), Ireland (29), the Netherlands (24), Norway (19), South Africa (18) and Sweden (14). The following 26 countries contributed between one and seven respondents: Albania, Algeria, Austria, Belgium, Bosnia, Bulgaria, Croatia, Czechia, Estonia, Faroe Islands, Finland, France, Greece, Iceland, India, Italy, Israel, Lithuania, Poland, Portugal, Romania, Slovakia, Slovenia, Spain, Switzerland, Ukraine.

Most participants $(1283 ; 84.6 \%)$ replied 'Yes' to 'Do you think you were prescribed antidepressant medication to treat depression?' Of the 485 who reported their primary diagnosis, the most commonly reported diagnoses were: Depression - 30.1\%; Bi-Polar Disorder 21.6\%; Schizophrenia spectrum disorders - 19.9\%: Personality Disorders - 8.7\%; Post Traumatic Stress Disorder - 3.5\%, and Anxiety Disorders - 2.6\%.

Although the focus of this article is the adverse effects of ADs, the respondents' views on whether the drugs were helpful are important characteristics of the sample. Positive outcome was assessed with two questions: (i) 'As a result of taking antidepressants, my depression was ....' and (ii) 'When taking antidepressants my quality of life is ....' each followed by a five point multiple choice scale. Table 1 shows that about two thirds $65.2 \%$ ) thought the drugs reduced their depression ('greatly' or slightly'), while $14.5 \%$ reported that they made the depression worse ('slightly' or 'a lot'). Similarly 60.9\% reported that their Quality of Life was 'improved', while $21.2 \%$ thought it was made 'worse'.

Table 1. Perceived efficacy of antidepressant medication.

\begin{tabular}{|c|c|c|c|c|c|}
\hline $\begin{array}{c}\text { 'As a result of ADs my } \\
\text { depression was.....' }\end{array}$ & $\begin{array}{l}\text { Greatly } \\
\text { reduced }\end{array}$ & $\begin{array}{l}\text { Slightly } \\
\text { reduced }\end{array}$ & Unchanged & $\begin{array}{l}\text { Slightly } \\
\text { worse }\end{array}$ & A lot worse \\
\hline
\end{tabular}




\begin{tabular}{|c|c|c|c|c|c|}
\hline$(\mathrm{n}=1475)$ & $29.9 \%$ & $35.3 \%$ & $20.3 \%$ & $4.9 \%$ & $9.6 \%$ \\
\hline $\begin{array}{c}\text { 'As a result of ADs my } \\
\text { quality of life was.....' }\end{array}$ & $\begin{array}{c}\text { Greatly } \\
\text { improved }\end{array}$ & $\begin{array}{c}\text { Slightly } \\
\text { improved }\end{array}$ & Unchanged & $\begin{array}{c}\text { Slightly } \\
\text { worse }\end{array}$ & A lot worse \\
\hline (n=1488) & $24.7 \%$ & $36.2 \%$ & $17.9 \%$ & $7.7 \%$ & $13.5 \%$ \\
\hline
\end{tabular}

\subsection{Total Adverse Effects}

The side effects section was completed by 1,431 respondents. Nearly all $(97.3 \%)$ reported at least one of the 20 side effects; with $83.3 \%$ reporting five or more, and $61.2 \%$ reporting ten or more. The mean number of adverse effects per respondent was 11.22 (s.d. 5.85).

Participants reported an average of 3.02 (s.d. 4.02) of the effects at the 'severe' 'level. Table 2 shows that 16 of the 20 side effects listed in the questionnaire were reported by more than half the respondents, most commonly: 'Feeling emotionally numb' (70.6\%), 'Feeling foggy or detached' (70.0\%); 'Feeling not like myself' (66.2\%), 'Sexual difficulties' (66.1\%),

'Drowsiness' (62.7\%), and 'Reduction in positive feelings' (60.4\%).

The mean Total Adverse Effects (TAE) score was 21.02 (s.d.14.12).

\subsection{The Antidepressants and Antipsychotics Group}

The 499 respondents who had taken both ADs and APs (AD+AP) were younger $(X=42.8$ years) than those who had only taken ADs (46.3 years), $(\mathrm{t}=4.84 . \mathrm{df}=1049.8, \mathrm{p}<.0001)$; but this was unrelated to gender.

Of the 499, 478 completed the side effects section of the questionnaire. This AD+AP group reported a significantly greater mean number of symptoms (12.87) than the AD only group (10.39) $(\mathrm{t}=4.55$, df 934.1, $\mathrm{p}<.0001)$. The TAE mean of the AD+AP group $(25.84$, s.d.14.56) was also significantly greater than the AD only group $(18.60$, s.d.13.29) $(\mathrm{t}=9.16$, df $885.4, p<.0001)$. Table 2 shows that the $A D+A P$ respondents had experienced each of the 
20 effects to a significantly greater degree than the AD only group. The largest difference was for Suicidality, which was reported by $65.9 \%$ of the AD+AP group $(24.7 \%$ at the severe level) compared to $42.5 \%$ of the $\mathrm{AD}$ only group (10.3\% severe).

Table 2 . Percentages reporting each of 20 adverse effects, with and without antipsychotics.

\begin{tabular}{|c|c|c|c|}
\hline & $\begin{array}{c}\text { Total } \\
\text { sample } \\
(n=1431)\end{array}$ & $\begin{array}{l}\text { ADs only } \\
(n=953)\end{array}$ & $\begin{array}{c}\text { ADs + APs } \\
(n=478)\end{array}$ \\
\hline Feeling emotionally numb & 70.6 & 66.1 & $79.7 * * *$ \\
\hline Feeling foggy or detached & 70.0 & 65.1 & $79.7 * * *$ \\
\hline Feeling not like myself & 66.2 & 61.4 & $75.9 * * *$ \\
\hline Sexual difficulties & 66.1 & 64.2 & 69.9* \\
\hline Drowsiness & 62.7 & 59.6 & $68.8 * * *$ \\
\hline Reduction in positive feelings & 60.4 & 55.2 & $70.9 * * *$ \\
\hline Weight gain & 60.1 & 55.8 & $68.6 * * *$ \\
\hline Dry mouth & 59.3 & 54.6 & $68.6 * * *$ \\
\hline Distorted dreams & 59.2 & 55.7 & $66.1 * * *$ \\
\hline Withdrawal effects & 58.9 & 55.4 & $65.9 * * *$ \\
\hline Agitation & 58.0 & 52.9 & $68.2 * * *$ \\
\hline Insomnia & 57.7 & 55.7 & $61.5 * * *$ \\
\hline Caring less about others & 54.5 & 49.9 & $63.6 * * *$ \\
\hline Dizziness & 51.6 & 47.5 & $59.8 * * *$ \\
\hline Headaches & 50.4 & 47.1 & $56.9 * * *$ \\
\hline Suicidality & 50.3 & 42.5 & $65.9 * * *$ \\
\hline Nausea & 46.8 & 43.3 & $53.8 * * *$ \\
\hline Feeling aggressive & 41.0 & 37.6 & $47.9 * * *$ \\
\hline
\end{tabular}




\begin{tabular}{|l|c|c|c|}
\hline Addiction & 40.5 & 36.8 & $47.7^{* *}$ \\
\hline Tremors & 37.4 & 32.3 & $47.5^{* * *}$ \\
\hline Total Adverse Effects (TAE) $^{\text {a }}$ & 21.02 & 18.60 & $25.84^{* * *}$ \\
\hline Mean number of adverse effects $^{\mathrm{b}}$ & 11.22 & 10.39 & $12.87^{* * *}$ \\
\hline
\end{tabular}

$\mathrm{a}=$ range $0-60$

$\mathrm{b}=$ range $0-20$

$*<01 ; * *<.001 ; * * * .0001$ (greater than ADs only group)

\subsection{The Antidepressant Only Group}

In order to reduce potential contamination of the rates of the side effects by the influence of APs, and so as to facilitate comparisons with the largest similar survey to date, in New Zealand [18], the findings for the 1,018 people who had taken ADs but not APs are presented separately. They are then analysed, like the New Zealand survey, in terms of gender, age and duration of treatment.

Of these 1,018 people, 953 completed the side effects section of the survey (see Tables 2 and 3). The mean number of adverse effects in this group was 10.39 (s.d. 5.83), and the mean TAE score was 18.60 (s.d. 13.29). Most (97.0\%) reported at least one of the 20 side effects; with $80.3 \%$ reporting five or more, and $54.7 \%$ reporting ten or more. The mean number of adverse effects per respondent was 10.39 (s.d. 5.83). Table 2 shows that 12 of the 20 side effects listed in the questionnaire were reported by more than half the respondents, most commonly: 'Feeling emotionally numb' (66.1\%), 'Feeling foggy or detached' (65.1\%), 'Sexual difficulties' (64.2\%) and 'Feeling not like myself' (61.4\%). The mean Total Adverse Effects (TAE) score was 18.60 (s.d.13.29).

\subsubsection{Gender}


Gender was related to neither mean number of adverse effects nor TAE mean scores.

Table 3 shows, however, that two of the 20 specific adverse effects were reported to a greater degree by men: Sexual difficulties and Caring less about others (both at the $\mathrm{p}<.01$ level). For example $58.2 \%$ of the men reported Caring less about others, compared to $46.6 \%$ of the women.

\subsubsection{Age}

Age was negatively correlated with number of adverse events $(r h o=.18, \mathrm{p}<.0001)$ and to TAE $(r h o=.10, \mathrm{p}<.0001)$. Age was significantly negatively correlated to eleven individual adverse effects, (nine at the $\mathrm{p}<.0001$ level; see Table 3), most strongly with Nausea and Feeling emotionally numb. Age was positively related only to Dry mouth $(\mathrm{p}<.001)$.

\subsubsection{Treatment duration}

The 549 who had taken ADs for more than three years reported a significantly higher number of adverse effects (10.80) than the 404 who had taken them for three years or less $(9.81)(\mathrm{t}=2.60, \mathrm{df} 950, \mathrm{p}<.01)$, and a higher TAE mean $(19.75$ vs. 17.01) $(\mathrm{t}=3.16$, df 950, $\mathrm{p}<.01$ ). Table 3 shows that five adverse effects were reported at a higher level by the group on $\mathrm{ADs}$ for more than three years (all at the $\mathrm{p}<.0001$ level), with the biggest differences being for Addiction, Withdrawal effects and Weight Gain. For example, 26.5\% of those on ADs for three years or less reported Addiction to ADs (10.3\% severe),compared to $44.5 \%$ of those on them for over three years (19.9\% severe).

Table 3. Percentages of respondents who took only antidepressants reporting each of 20 adverse effects, analysed by gender, age and treatment duration (more than three years vs. three years or less); with findings of the 2014 New Zealand survey in brackets.

\begin{tabular}{|l|l|l|l|l|l|}
\hline $\mathrm{n}=953$ & $\%$ & $\%$ & & & treatment \\
\hline
\end{tabular}




\begin{tabular}{|c|c|c|c|c|c|}
\hline & any & severe & gender & age & duration \\
\hline Feeling emotionally numb & $\begin{array}{c}66.1 \\
(60.4)\end{array}$ & $\begin{array}{c}18.2 \\
(13.5)\end{array}$ & & $\begin{array}{l}\mathrm{Y}^{* * *} \\
\mathrm{Y}^{* * *}\end{array}$ & \\
\hline Feeling foggy or detached & $\begin{array}{c}65.1 \\
(-)\end{array}$ & $\begin{array}{c}16.3 \\
(-)\end{array}$ & & $\mathrm{Y}^{* * *}$ & \\
\hline Sexual difficulties & $\begin{array}{c}64.2 \\
(62.3)\end{array}$ & $\begin{array}{c}20.0 \\
(14.1)\end{array}$ & $\begin{array}{l}\mathbf{M}^{*} \\
M^{* *}\end{array}$ & & $\begin{array}{l}>3 y r s * * * \\
>3 y r s * *\end{array}$ \\
\hline Feeling not like myself & $\begin{array}{c}61.4 \\
(52.4) \\
\end{array}$ & $\begin{array}{c}16.7 \\
(11.0) \\
\end{array}$ & & $\begin{array}{l}\mathrm{Y}^{* * *} \\
\mathrm{Y}^{* * *}\end{array}$ & $\leq 3 y r s^{*}$ \\
\hline Drowsiness & $\begin{array}{c}\mathbf{5 9 . 6} \\
(57.8)\end{array}$ & $\begin{array}{l}10.3 \\
(8.6)\end{array}$ & & $\mathrm{Y}^{* * *}$ & \\
\hline Weight gain & $\begin{array}{c}55.8 \\
(56.4) \\
\end{array}$ & $\begin{array}{c}14.0 \\
(12.2) \\
\end{array}$ & $\mathrm{F}^{*}$ & & $\begin{array}{l}>3 \mathrm{yrs} * * * \\
>3 \mathrm{yrs} * * *\end{array}$ \\
\hline Insomnia & $\begin{array}{c}55.7 \\
(-) \\
\end{array}$ & $\begin{array}{c}11.4 \\
(-)\end{array}$ & & & \\
\hline Distorted dreams & $\begin{array}{c}55.7 \\
(-)\end{array}$ & $\begin{array}{c}11.0 \\
(-)\end{array}$ & & & \\
\hline Withdrawal effects & $\begin{array}{c}55.4 \\
(54.9)\end{array}$ & $\begin{array}{c}23.8 \\
(25.0)\end{array}$ & & $\mathrm{Y}^{* * *}$ & $\begin{array}{l}>3 y r s * * * \\
>3 y r s * * *\end{array}$ \\
\hline Reduction in positive feelings & $\begin{array}{c}55.2 \\
(41.7)\end{array}$ & $\begin{array}{l}13.2 \\
(8.0)\end{array}$ & $M^{*}$ & & \\
\hline Agitation & $\begin{array}{c}52.9 \\
(46.9) \\
\end{array}$ & $\begin{array}{c}9.2 \\
(7.0)\end{array}$ & & $\begin{array}{l}\mathrm{Y}^{* *} \\
\mathrm{Y}^{* * *}\end{array}$ & \\
\hline Dry mouth & $\begin{array}{c}\mathbf{5 4 . 6} \\
(57.6)\end{array}$ & $\begin{array}{l}10.7 \\
(9.7)\end{array}$ & & $0 * * *$ & $\begin{array}{l}>3 y r s * * * \\
>3 y r s * *\end{array}$ \\
\hline Caring less about others & $\begin{array}{c}49.9 \\
(38.8)\end{array}$ & $\begin{array}{c}11.0 \\
4.9\end{array}$ & $\begin{array}{l}\mathbf{M}^{*} \\
\mathrm{M}^{* * *}\end{array}$ & & \\
\hline Dizziness & $\begin{array}{c}47.5 \\
(45.2)\end{array}$ & $\begin{array}{c}6.3 \\
(4.8) \\
\end{array}$ & & $\begin{array}{l}\mathrm{Y}^{* * *} \\
\mathrm{Y}^{* * *}\end{array}$ & \\
\hline Headaches & $\begin{array}{c}47.1 \\
(47.0) \\
\end{array}$ & $\begin{array}{c}6.4 \\
(5.1) \\
\end{array}$ & & $\begin{array}{l}\mathrm{Y}^{*} \\
\mathrm{Y}^{* * *}\end{array}$ & \\
\hline Nausea & $\begin{array}{c}43.3 \\
(39.4) \\
\end{array}$ & $\begin{array}{c}5.1 \\
(4.6) \\
\end{array}$ & & $\begin{array}{l}\mathrm{Y}^{* * *} \\
\mathrm{Y}^{* * *}\end{array}$ & \\
\hline Suicidality & $\begin{array}{c}42.5 \\
(38.9) \\
\end{array}$ & $\begin{array}{l}10.5 \\
(7.8) \\
\end{array}$ & & $\begin{array}{l}\mathrm{Y}^{* * *} \\
\mathrm{Y}^{* * *} \\
\end{array}$ & $>3 y r s^{*}$ \\
\hline Feeling aggressive & $\begin{array}{c}37.6 \\
(28.0) \\
\end{array}$ & $\begin{array}{c}7.1 \\
(4.9) \\
\end{array}$ & $M^{*}$ & $\mathrm{Y}^{* * *}$ & \\
\hline Addiction & $\begin{array}{c}36.8 \\
(27.4) \\
\end{array}$ & $\begin{array}{l}13.4 \\
(6.2) \\
\end{array}$ & & & $\begin{array}{l}>3 y r s * * * \\
>3 y r s * * *\end{array}$ \\
\hline Tremors & $\begin{array}{c}32.3 \\
(31.3) \\
\end{array}$ & $\begin{array}{c}4.8 \\
(4.5) \\
\end{array}$ & & & \\
\hline
\end{tabular}

$*<01 ; * *<.001 ; * * * .0001$

Age: spearman rank correlations $(\mathrm{Y}=$ younger age; $\mathrm{O}=$ older age $)$

Gender and Treatment Duration: t-test independent means

$(-)=$ this variable not included in New Zealand survey 


\subsection{Medication Types}

Of the 1151 in the total sample who identified their $\mathrm{AD}$, the most frequently named were: fluoxetine 223, 19.4\%; sertraline 175, 15.2\%; citalopram 157, 13.6\%; paroxetine $112,9.7 \%$; venlafaxine $112,9.7 \%$; and escitalopram $93,8.1 \%$. There were also 126 cases of tricyclic ADs (10.9\%), mostly amitriptyline. Fifty one (4.4\%) responded in ways that indicated use of multiple ADS (e.g. 'lots', 'various', 'Lost count of how many different ones').

Table 4 shows that there were no significant differences between the types of drugs in terms of the mean number of adverse effects. Citalopram, however, produced a lower mean TAE score than paroxetine, fluoxetine and tricyclics, all at the $p<.01$ level. For example: the mean TAE for citalopram (18.14) was significantly lower than the mean for paroxetine (23.44); $\mathrm{t}=3.15, \mathrm{df}=250, \mathrm{p}<.01$. Citalopram's TAE mean was also lower than the mean for the other six drug types combined (21.21); $\mathrm{t}=2.85, \mathrm{df}=233.1, \mathrm{p}<.01$. More specifically citalopram produced significantly lower means for Suicidality, Caring less about others, Reduction in positive feelings and Feeling aggressive (all at the $\mathrm{p}<.01$ level or beyond), with the biggest difference being for Caring less about others; $\mathrm{t}=3.63, \mathrm{df}=231.3, \mathrm{p}<.0001$.

Table 4 also shows that usage of multiple ADs produced both a significantly higher TAE mean $(\mathrm{p}<.0001)$ and a higher mean number of adverse effects $(\mathrm{p}<.01)$ than all seven individual drug types combined. (Use of multiple ADs was unrelated to age and gender).

Table 4. Total Adverse Effects scores, and number of adverse effects, by medication type.

\begin{tabular}{|l|c|c|c|}
\hline & $\mathrm{n}$ & $\begin{array}{l}\text { Mean 'Total Adverse } \\
\text { Effects' score } \\
\text { (and S.D.) }\end{array}$ & $\begin{array}{l}\text { Mean number of } \\
\text { adverse effects } \\
\text { (and S.D.) }\end{array}$ \\
\hline Paroxetine & 102 & $23.44(14.88)$ & $11.83(5.90)$ \\
\hline Fluoxetine & 205 & $22.25(14.38)$ & $11.55(5.74)$ \\
\hline
\end{tabular}




\begin{tabular}{|l|c|c|c|}
\hline Tricyclics & 115 & $22.79(15.17)$ & $11.53(5.91)$ \\
\hline Escitalopram & 90 & $20.32(14.80)$ & $11.09(6.05)$ \\
\hline Venlafaxine & 104 & $21.59(15.07)$ & $11.02(5.95)$ \\
\hline Sertraline & 171 & $19.18(12.90)$ & $10.51(5.31)$ \\
\hline Citalopram & 150 & $18.14^{\mathrm{a}, \mathrm{b}}(11.73)$ & $10.27(5.52)$ \\
\hline & & & $13.49^{\mathrm{d}}(5.48)$ \\
\hline Multiple ADs & 51 & $28.71^{\mathrm{c}}(14.80)$ & \\
\hline
\end{tabular}

a. Lower than Paroxetine, Fluoxetine, and Tricyclics $(\mathrm{p}<.01)$

b. Lower than the six other individual drug types combined $(p<.01)$

c. Higher than the seven drug types combined $(p<.0001)$

d. Higher than the seven drug types combined $(\mathrm{p}<.01)$

\subsection{Suicidality}

Suicidality was reported to be a side effect of taking ADs by $50.3 \%$ of the total sample, $42.5 \%$ of the $\mathrm{AD}$ only group, and $65.9 \%$ of the $\mathrm{AD}+\mathrm{AP}$ group. The percentages reporting 'severe' suicidality were $15.1 \%, 10.3 \%$, and $24.7 \%$ respectively. Suicidality was negatively correlated with age $(r h o=.12, \mathrm{p}<.0001)$, but was not related to gender. The specific adverse effects most strongly correlated with Suicidality were: Feeling not like self $(r h o=.58)$, Reduction in positive feelings $(r h o=.58)$ and Feeling aggressive $(r h o=.54)($ all $\mathrm{p}<.0001)$. (The specific tests reported here are for the AD only group, but the findings were very similar for the $\mathrm{AD}+\mathrm{AP}$ group and the sample as a whole).

Citalopram was significantly less likely than the other drugs combined to lead to suicidality $(\mathrm{t}=2.53, \mathrm{df}=236.3, \mathrm{p}<.0001)$. Both forms of polypharmacy significantly increased the rate of suicidality: multiple ADs $(t=3.38$, df 1072, $p<.001)$, and APs in addition to ADs $(\mathrm{t}=9.92$, df 837.3, $\mathrm{p}<.0001)$. 


\subsection{Information about Adverse Effects}

In response to 'Did the doctor inform you of any possible side effects?' 520 (34.3\%) replied Yes, 973 (64.1\%) said No, and 24 (1.6\%) did not reply. Being informed was unrelated to age or gender, or to whether the prescriber was a GP or a Psychiatrist.

Those who had been informed about side effects reported fewer adverse effects on average (9.75) than those not informed $(12.01)(\mathrm{t}=7.07 ; \mathrm{df}=1422, \mathrm{p}<.0001)$; and also produced a lower TAE mean $(36.71$ vs $43.36 ; t=8.69, \mathrm{df}=11180.9, \mathrm{p}<.0001)$. Every one of the 20 side effects was reported to a significantly greater extent by people who had not been informed about side effects $(18$ at the $p<.0001$ level $)$

Of the 520 who recalled being told about side effects, $371(71.3 \%)$ recalled one or more specific side effects they had been told about (see Table 5), most frequently Nausea (77) and Weight changes (75). A further 21 referred to a written list of effects being given, or read, to them.

Table 5. Frequency of adverse effects about which participants had been informed (6 or more).

\begin{tabular}{|l|l|l|l|}
\hline Nausea/vomiting & 77 & Increased depression & 22 \\
\hline Weight/appetite changes & 75 & Anxiety & 17 \\
\hline Sleepiness/drowsiness/sedation & 56 & Mania/mood swings & 10 \\
\hline Dry mouth & 51 & Withdrawal symptoms/addiction & 9 \\
\hline Sexual dysfunction & 42 & Constipation & 8 \\
\hline Suicidality & 35 & Tremors & 8 \\
\hline Insomnia & 22 & Agitation/restlessness & 8 \\
\hline Dizziness & 26 & Loss of interest, emotions/lethargic & 8 \\
\hline Headaches & 22 & Blurred vision & 6 \\
\hline
\end{tabular}




\section{DISCUSSION}

This study confirms previous studies that have found that when AD users are asked directly they report an extensive range of adverse effects at very high frequencies. Thus this kind of survey can be a valuable adjunct to more traditional methodologies for assessing adverse drug effects, as can spontaneous reporting systems [24] and real-world data gathered from clinical practice [25].

Sixteen effects were experienced by more than half of the total sample. Amongst those who had only taken ADs the rates are slightly higher than those found in in the earlier New Zealand survey [18], but are quite similar overall. For example Feeling emotionally numb was reported by $66.1 \%$ in the current study and $60.4 \%$ in the New Zealand study. Furthermore, the three side effects introduced to the current study because of spontaneous reporting in the New Zealand study all produced very high response rates: Feeling foggy or detached (65.1\%), Insomnia (55.7\%) and Distorted dreams (55.7\%) (see Table 3).

The second major finding is the confirmation of very high rates of adverse effects in the emotional and interpersonal domains [12-17]. In both the current international study and the earlier New Zealand survey [18] Emotional numbing, Sexual difficulties, Feeling not like myself, Reduction in positive feelings and Caring less about others were extremely common. Similarly, a UK online survey of over $1,000 \mathrm{AD}$ users [26] found that $60 \%$ reported negative effects in at least one of the five interpersonal domains assessed (most commonly 'Sex life' and 'Work or study'). A recent examination of over 3,000 online comments by AD users found that 'Emotional and behavioral' adverse effects were reported far more than biological/medical effects such as Cardiovascular, Gastrointestinal or Metabolic [27]. All 
these findings contrast with more traditional studies of adverse effects, such as drug trials which have focussed, like most officially sanctioned checklists, on the adverse biological/medical effects [9-11].

There was some consistency between the New Zealand and current study in terms of gender and age. In both studies men were more likely than women to report Sexual difficulties and Caring less about others. In both studies younger people reported more adverse effects overall, particularly for Feeling emotionally numb, Feeling not like myself, Suicidality, Dizziness, and Nausea.

\subsection{Polypharmacy}

Presenting the rates of adverse effects for those taking only ADs is a sensible way to try to ensure that the reported effects are caused specifically by ADs. They underestimate, however, rates in the real world, where it is commonplace for people to be on multiple types of psychiatric medication $[28,29]$. Therefore the rates for the total sample in the current study may be the most accurate account of the adverse effects being experienced by AD users. The finding that every one of the 20 adverse effects was significantly more common amongst those who took both ADs and APs than among those who took only ADs is important. The interactive negative effects of different types of psychiatric drugs is rarely studied in traditional drug trials.

In the UK survey of over 1,000 AD users [26] more than half were taking one or more additional psychiatric drugs. The number of types of medication correlated with overall severity of side effects. The number of medication types was also related to each of the six specific types of adverse effect. For example, while $44 \%$ of those on antidepressants alone reported an adverse effect on their sex life, this was the case for $54 \%$ of those on 
antidepressants plus one other psychiatric medication, and $63 \%$ of those on three additional medications. A 2013 review [28] concluded:

While evidence for the added benefit of psychiatric polypharmacy is limited, there is growing evidence regarding the increased adverse effects associated with such combinations.

In the current study, three specific adverse effects were reported by three out of every four of the participants who took both ADs and APs: Feeling emotionally numb, Feeling foggy or detached, and Feeling not like myself.

\subsection{Suicidality}

Since the 1990s studies have documented that ADs increase suicidality for a small number of people $[30,31]$. Asking AD users directly, however, suggests that the problem may be far greater than originally thought. In the current study 'suicidality'... 'as a result of taking the antidepressant' was reported by $42.5 \%$ of the AD only group. This corroborates the $38.9 \%$ finding in the large New Zealand survey [18]. The rates at the 'severe' level of suicidality were $10.5 \%$ and $7.8 \%$ respectively. In both studies the likelihood of experiencing suicidality increased the longer the person stayed on the ADs. Furthermore, nearly two in every three people (65.9\%) taking both ADs and APs reported suicidality (24.7\% at the 'severe' level). The other form of polypharmacy, multiple ADs, also increased risk of suicide compared to taking just one $\mathrm{AD}$.

Increased suicidality as a result of ADs is especially strong in children, adolescents and young adults $[32,33]$, leading the F.D.A. to place a 'Black Box' warning, in 2006, on all ADs for people under the age of 26 [32]. The current study excluded children but, like the New Zealand survey, confirmed that younger adults are indeed even more likely to report suicidality than older adults. 


\subsection{Withdrawal Effects and Addiction}

More than half of participants taking only ADs (55.4\%) reported Withdrawal effects (23.8\% at the 'severe' level). This is consistent with the $54.9 \%$ in the New Zealand survey [18]. Furthermore, about a third reported Addiction in both studies (36.8\% and 27.4\% respectively). In both studies both Addiction and Withdrawal effects were, unsurprisingly perhaps, reported significantly more by people who had been on ADs for more than three years. For example, in the New Zealand study $74 \%$ of those on ADs for more than three years reported Withdrawal symptoms, and $46 \%$ of those reporting the symptoms described them as 'severe' [34]. A recent Dutch study found that of 692 users of tapering strips 671 (97\%) had experienced some level of withdrawal effects when they had previously tryed to stop their ADs; and that 339 of those $671(51 \%)$ reported the severity of the withdrawal as 7 on a 7 point scale [35].

The issue of whether ADs should be considered addictive has polarised opinion. In a survey of over 2,000 members of the British public, many of whom of course were either taking ADs or knew people who were taking them, 78\% described ADs as addictive [36]. The Diagnostic and Statistical Manual for Mental Disorders [37] requires that two of eleven criteria are met for 'substance dependence'. The current study and the large New Zealand survey [18] indicate that ADs may meet at least four of these criteria for many people: 'Withdrawal manifesting as a characteristic syndrome', 'Wanting to cut down or quit but not being able to do it', 'Continued use despite persistent or recurring social or interpersonal problems caused or made worse by substance use' and 'Stopping or reducing important social, occupational, or recreational activities due to substance use.'

Nevertheless, the only reference to the issue in the American Psychiatric Association Practice Guideline for depression is 'Common misperceptions about antidepressants (e.g. 
they are addictive) should be clarified' [38]. (The authors listed, between them, over 80 instances of receiving payments from drug companies). In the UK the Royal College of Psychiatrists (R.C.P.) states: 'We would like to reassure readers that despite some people having symptoms of withdrawal when stopping antidepressants, antidepressants are not addictive' [39]. In February, 2018 the President of the R.C.P. and the Chair of its Psychopharmacology Committee jointly informed the public that 'We know that in the vast majority of patients, any unpleasant symptoms experienced on discontinuing antidepressants have resolved within two weeks of stopping treatment' [40].

The term 'Discontinuation Syndrome' was introduced in 1996, at a 'closed symposium' in Phoenix, Arizona [41]. The gathering was funded by Eli Lilly. The 'Discontinuation Consensus Panel' consisted of industry funded professionals who argued that AD withdrawal is very different from withdrawal from benzodiazepines.

Researchers at the Nordic Cochrane Centre disagree with the A.P.A, the R.C.P, and Eli Lilly spokespersons. Their 2012 review [42] of 45 papers on benzodiazepines and 31 papers on SSRIs concluded that 'Withdrawal reactions to SSRIs appear to be similar to those for benzodiazepines; referring to these reactions as part of a dependence syndrome in the case of benzodiazepines, but not selective serotonin re-uptake inhibitors, does not seem rational'.

The disputes seem to rest primarily on disagreements about the definition of 'addiction'. An approach which circumvents these disagreements is to allow people who have taken ADs to interpret the term 'addiction' as they wish, thereby respecting their actual personal experience. A 2004 review of studies of 'Patients' preferences in the treatment of depressive disorder in primary care' found that 'Antidepressants were often regarded as addictive' [43]. A 2014 review [12], of studies of 'Patient-centred perspectives on antidepressant use', concurred, reporting that 'the most frequently mentioned reason for a negative opinion of antidepressants is that they may be addictive'. High rates of addiction and withdrawal effects 
among AD users, when asked directly, have been found in Denmark [44], the Netherlands $[35,45]$, Scotland [46] and the USA [13, 47]. A 2012 survey by the Royal College of Psychiatrists in the UK found that of 817 people who had stopped taking ADs, $63 \%$ experienced withdrawal symptoms [48].

High rates of addiction and difficulties withdrawing are consistent with findings that the ever increasing prescription rates of ADs are not explicable in terms of increased incidence of depression, or changes in help-seeking behavior [49], but rather in terms of increases in repeat prescriptions. A study of 189,851 GP patients in the UK found that a doubling of prescribing over eight years was explained not by increases in new prescriptions but by a doubling of the number of prescriptions per patient [50].

\subsection{Information}

In the current study only one third of AD users (34\%) recalled being told about any side effects. This is lower than the $64 \%$ in the New Zealand survey and the findings of two British studies, 59\% [51] and 55\% [52]. Together, these four studies suggest that between one and two thirds of $\mathrm{AD}$ recipients are told nothing about side effects. What information that is imparted seems to focus on biological side effects. In both the current study and the New Zealand study [53] the side effects that people were most commonly warned about were nausea and weight gain. Less than five percent were warned about increased suicidality in either study. None were told about feeling less like themselves or about possible effects on their relationships with others (other than sexual dysfunction). In both studies fewer than two percent were told anything about withdrawal effects [53]. This breaches the fundamental ethical principle of 'informed consent' which is binding on all health professionals.

\subsection{Strengths and Limitations}


This is a self selected, convenience sample, despite being the second largest sample ever directly surveyed. Although it is more international than the original New Zealand based survey, almost the entire sample lived in Europe, North America or Australasia. The over representation of women (70.5\%) is less of an issue as women are prescribed ADs approximately twice as often as men. The very high rates of adverse effects raises the possibility that the sample is biased towards people who had found ADs ineffective and therefore may have had 'an axe to grind'. However, two thirds (65.2\%) reported that the ADs had reduced their depression. The study relies on self-report, but so do most traditional studies of the effects of drugs, positive and negative. The fact that some of the reports are for events many years previously is more of a problem. For example, some participants may actually have been given more information about adverse effects than they could recall years later.

The failure to gather data about the duration of withdrawal effects is also a limitation. A recent review [54] found that they typically 'last a few weeks' but identified 'many variations... including longer persistence of disturbances' and two studies documenting withdrawal symptoms up to one year following paroxetine discontinuation. More research is urgently needed in this area.

It is possible that some respondents may not have taken ADs and may be responding on behalf of a loved one or may even have, for some unknown reason, fabricated a set of responses. Safeguards were in place, however, against repeat responders and people who mistakenly thought their drug was an AD when it was not (see Methods). Finally, the study did not allow for possible confounding variables such as substance abuse and other medicines besides APs. 


\section{CONCLUSION}

As noted earlier, the experience of patients is finally receiving the attention it so obviously warrants. Directly surveying patients, and using PROMs, helps to 'ensure that research is both robust and of maximum value for the use of medicinal products, therapy, or health services'.... and 'reflects the ongoing health service commitment of involving patients and the public within the wider context of the development and evaluation of health care service delivery and quality improvement.' $[19, \mathrm{p} .61]$

Asking people directly about their experience of ADs reveals that their adverse effects may be far more varied and prevalent and damaging than previously realised when relying on more traditional research methodologies. Together with the consistent findings that ADs are no more effective than placebo for many recipients, the findings of these recent direct-toconsumer surveys produce a cost-benefit analysis that cannot justify the current extraordinarily high prescription rates of ADs. A first step towards reducing inappropriate prescribing would be for all prescribers to fully inform all potential recipients of all potential side effects, including suicidality, emotional blunting and withdrawal effects. Psychiatric polypharmacy should be a last resort rather than standard practice. It seems that health services need to challenge the denial and minimization of the drug companies and some professional bodies and urgently develop drug withdrawal services for the millions already trying to come off these drugs but experiencing withdrawal effects which are sometimes severe and protracted.

\section{CONFLICT OF INTEREST}

Both authors declare no financial, personal or potential conflicts of interest. 


\section{REFERENCES}

[1] Ilyas S, Moncrieff J. Trends in prescriptions and costs of drugs for mental disorders in England, 1998 -2010. Br J Psychiatry 2012; 200: 393-8.

[2] Kantor E, Rehm C, Haas J, Chan A, Giovannucci E. Trends in prescription drug use among adults in the United States from 1999-2012. J Am Med Assoc 2015; 314: 1818-30.

[3] NHS Digital. Prescriptions dispensed in the community 2006-2016. London: National Health Service; 2017.

[4] Khan A, Brown W. Antidepressants versus placebo in major depression: an overview. World Psychiatry 2015; 14: 294-300.

[5] Khan A, Khan S, Brown W. Are placebo controls necessary to test new antidepressants and anxiolytics? Int J Neuropsychopharmacol 2002; 5: 193-7.

[6] Moncrieff J. Antidepressants: misnamed and misrepresented. World Psychiatry 2015; 14: $302-3$.

[7] Kirsch I, Deacon B, Huedo-Medina T, et al. Initial severity and antidepressant benefits: a meta-analysis of data submitted to the Food and Drug Administration. PLOS Med 2008; 20085: $260-8$.

[8] Cipriani A, Furukawa T, Salanti G., et al. Comparative efficacy and acceptability of 21 antidepressant drugs for the acute treatment of adults with major depressive disorder: a systematic review and network meta-analysis. Lancet 2018; 391: 1357-66.

[9] Jakobsen J, Katakam K, Schou A, et al. Selective serotonin reuptake inhibitors versus placebo in patients with major depressive disorder. A systematic review with meta-analysis and Trial Sequential Analysis. BMC Psychiatry 2017; 17: 58.

[10] Uher R, Farmer A, Henigsberg N, et al. Adverse reactions to antidepressants. Br J Psychiatry 2009; 195: 202-10.

[11] Adkins D, Clark S, Åberg K, et al. Genome-wide pharmacogenomic study of citalopraminduced side effects in STAR*D. Transl Psychiatry 2012; 2: e129. 
[12] Gibson K, Cartwright C, Read J. Patient-centred perspectives on antidepressant use: a narrative review. Int J Ment Health Nurs 2014; 43: 81-99.

[13] Givens J, Datto C, Ruckdeschel K, et al. Older patients' aversion to antidepressants. J General Intern Med 2006; 21: 146-51.

[14] Goldsmith L, Moncrieff J. The psychoactive effects of antidepressants and their association with suicidality. Curr Drug Saf 2011; 6: 1-7.

[15] Liebert R, Gavey N. 'I Didn't Just Cross a Line I Tripped Over an Edge': experiences of serious adverse effects with selective serotonin reuptake inhibitors. NZ J Psychol 2008; 7: 3848.

[16] Pestello F, Davis-Berman J. Taking anti-depressant medication: a qualitative examination of internet postings. J Ment Health 2008; 17: 349-60.

[17] Price J, Cole V, Goodwin G. Emotional side-effects of selective serotonin reuptake inhibitors: qualitative study. Br J Psychiatry 2009; 195: 211-217.

[18] Read J, Cartwright C, Gibson K. Adverse emotional and interpersonal effects reported by 1,829 New Zealanders while taking antidepressants. Psychiatry Res 2014; 216: 67-73.

[19] Weldring T, Smith, S. Patient-Reported Outcomes (PROs) and Patient-Reported Outcome Measures (PROMs). Health Serv Insights 2013; 6: 61-8.

[20] Krägeloh C, Czuba K, Billington R, Kersten P, Siegert R. Using feedback from PatientReported Outcome Measures in mental health services: A scoping study and typology. Psychiatr Serv 2015; 66: 224-41.

[21] Gibson K Cartwright C, Read, J. 'In my life antidepressants have been....' : a qualitative analysis of users' diverse experiences of antidepressants. BMC Psychiatry 2016; 16: 135.

[22] Read J, Gibson K, Cartwright C, Shiels C, Dowrick C, Gabbay M. The nonpharmacological correlates of self-reported efficacy of antidepressants. Acta Psychiatr Scand 2015; 131: 43445.

[23] Read J, Gibson K, Cartwright C, Shiels C, Magliano L. Beliefs of people taking antidepressants about the causes of their own depression. J Affect Dis 2015; 174: 150-6. 
[24] Kim S, Park K, Kim M, Yang B, Choi H, Park B. Data-mining for detecting signals of adverse drug reactions of fluoxetine using the Korea Adverse Event Reporting System (KAERS) database. Psychiatry Res 2017; 256: 237-42.

[25] Degli Esposti L, Piccinni C, Sangiorgi D, Fagiolini A, Buda S. Patterns of antidepressant use in Italy: therapy duration, adherence and switching. Clin Drug Investig 2015; 35: 735-42.

[26] Read J, Gee A, Diggle J, Butler H. The interpersonal adverse effects reported by 1,008 users of antidepressants; and the incremental impact of polypharmacy. Psychiatry Res 2017; 256: $423-7$.

[27] Hughes S, Lacasse J, Fuller R, Spaulding-Givens J. Adverse effects and treatment satisfaction among online users of four antidepressants. Psychiatry Res 2017; 255: 78-86.

[28] Kukreja S, Kalra G, Shah N, Shrivastava A. Polypharmacy in psychiatry: a review. Mens Sana Monogr 2013; 11: 82-99.

[29] Mojtabai R, Olfson M. National trends in psychotropic medication polypharmacy in officebased psychiatry. Arch Gen. Psychiatry 2010; 67: 26-36.

[30] Makris G, Reutfors J, Ösby U, et al. Suicide seasonality and antidepressants: a register-based study in Sweden. Acta Psychiatr Scand 2013; 127: 117-25.

[31] Nassir G, Vohringer P, Whitham E. Antidepressants from a public health perspective: reexamining effectiveness, suicide, and carcinogenicity. Acta Psychiatr Scand 2013; 127: 893.

[32] Food and Drug Administration. Clinical review: relationship between antidepressant drugs and suicidality in adults, 2006. www.fda.gov/ohrms/dockets/ac/06/briefing/2006-4272b1-01FDA.pdf. [accessed Feb 2018].

[33] Hammad T, Laughren T, Racoosin J. Suicidality in pediatric patients treated with antidepressant drugs. Arch Gen Psychiatry 2006; 63: 332-9.

[34] Cartwright C, Gibson K, Read J, Cowan O, Dehar T. Long-term antidepressant use: patient perspectives of benefits and adverse effects. Patient Pref Adher 2016; 10: 1401-7. 
[35] Van Os J, Groot P. 2018. Antidepressant tapering strips to help people come off medication more safely. Psychosis Psychol Soc Integrative Approaches, doi.org/10.1080/17522439.2018.1469163

[36] Priest R, Vize C, Tylee A. Lay people's attitudes to treatment of depression. BMJ 1996; 313: $858-9$.

[37] American Psychiatric Association. Diagnostic and statistical manual of mental disorders. $5^{\text {th }}$ ed. Washington D.C.: A.P.A.; 2013.

[38] American Psychiatric Association. Practice guideline for the treatment of patients with major depressive disorder. 3rd ed. Washington D.C.: A.P.A.; 2010.

[39] Royal College of Psychiatrists. Antidepressants. London: R.C.P.; 2015 www.rcpsych.ac.uk/health/advice/treatmentswellbeing/antidepressants.aspx. [accessed Feb 2018].

[40] Burns W, Baldwin D. (2018). Letter to the editor. The Times; Feb. 24.

[41] Schatzberg A, Haddad P, Kaplan E. et al. Seretonin Reuptake Inhibitor Discontinuation Symndrome: a hypothetical defintion. Discontinuation Consensus Panel. J Clin Psychiatry 1997; 58 (suppl 7): 5-10.

[42] Nielsen M, Hansen E, Gøtzsche P. What is the difference between dependence and withdrawal reactions? A comparison of benzodiazepines and selective serotonin re-uptake inhibitors. Addict 2012; 107: 900-08.

[43] van Schaik D, Klijnb A, van Hout H, van Marwijk H, Beekman A, van Dyck R. Patients' preferences in the treatment of depressive disorder in primary care. Gen Hosp Psychiatry 2004; 26: 184-9.

[44] Kessing L, Hansen H, Demyttenaere K, Bech P. Depressive and bipolar disorders: patients' attitudes and beliefs towards depression and antidepressants. Psychol Med 2005; 35: 1205-13.

[45] Hoencamp E, Stevens A, Haffmans J. Patients' attitudes toward antidepressants. Psychiatr Serv 2002; 53: 1180-1.

[46] Stone J, Durrance D, Wojcik W, Carson A, Sharpe M. What do medical outpatients attending a neurology clinic think about antidepressants? J Psychosom Res 2004; 56: 293-5. 
[47] Bogner H, Cahill E, Frauenhoffer C, Barg F. Older primary care patient views regarding antidepressants: a mixed methods approach. J Ment. Health 2009; 18: 57-64.

[48] Royal College of Psychiatrists. Coming off antidepressants. London: R.C.P.; 2012. www.rcpsych.ac.uk/healthadvice/treatmentswellbeing/antidepressants/comingoffantidepressa nts.aspx. [accessed Feb 2018].

[49] Munoz-Arroyo R, Sutton M, Morrison J. Exploring potential explanations for the increase in antidepressant prescribing in Scotland using secondary analyses of routine data. Br J Gen Pract 2006; 56: 423-8.

[50] Moore M, Yuen H, Dunn N, Mullee M, Maskell J Kendrick T. Explaining the rise in antidepressant prescribing: a descriptive study using the general practice research database. Br Med J 2009; 339: b3999.

[51] Byng R, Bury C, Weaver L. Patients' experiences of consultations for depression and predictors of adherence to antidepressants. Prim Care Comm Psychiatry 2007; 12: 109-15.

[52] Mind. Antidepressants prescribed too quickly for too long. London; Mind; 2012. http://www.mind.org.uk/news/7546_antidepressants_prescribed_too_quickly_for_too_long_fi nds_mind_survey [accessed Feb 2018].

[53] Read J, Cartwright C, Gibson K. How many of 1,829 antidepressant users report withdrawal symptoms or addiction? Int J Ment Health Nurs 2018, doi: 10.1111/inm.12488

[54] Fava G, Gatti A, Belaise C, Guidi J, Offidani E. Withdrawal Symptoms after Selective Serotonin Reuptake Inhibitor discontinuation: a systematic review. Psychother Psychosom, 2015; 84: 72-81. 